\title{
Educational Research in the Context of Rural Revitalization: Take Papers of CNKI Database from 2000 to 2021 As an Example
}

\author{
Wei An, Jie Wu \\ Education Bureau of Zhoucun District, Zibo City, Shandong, China
}

\begin{abstract}
For a long time, rural revitalization has been a topic of concern. After it was put forward in the form of a policy in 2017, it has further received research feedback in many fields, and the education field is no exception. This article is based on the quantitative analysis of the reports in the CNKI database, with rural revitalization as the theme of educational research from 2000 to 2021. We summarized its development trends and research priorities. We found that after 2017, there has been a surge in education research related to rural revitalization, focusing on three aspects: vocational education, teacher plight, and education construction. At present, the rural revitalization strategy is still in its infancy. Grasping the research focus in time and referring to international experience can provide a more comprehensive theoretical basis for the realization of rural revitalization, promote the flexible change of research focus, and facilitate the effective implementation of policies.
\end{abstract}

Science Insights Education Frontiers 2021; 10(1):1381-1397.

Doi: 10.15354/sief.21.or052

How to Cite: An, W., \& Wu, J. (2021). Educational research in the context of rural revitalization: Take papers of CNKI database from 2000 to 2021 as an example. Science Insights Education Frontiers, 10(1):1381-1397.

Keywords: Rural Revitalization, Rural Education, Vocational Education, Teacher Team Building, Policy Building 
$\mathrm{C}$

HINA's development contradictions have been changing. The people's growing demand for a better life and unbalanced and inadequate social development are the main contradictions at this stage in China. This is particularly prominent in China's urban and rural issues. To promote rural development, China has successively introduced related policies. In 2017, the rural revitalization strategy was put forward; in 2018, the "Guiding Opinions" were issued. The foothold of this strategy and guidance is the modernization of agriculture and rural areas, and the development goals of industrial upgrading, technological progress, and sound systems are put forward. The rural revitalization strategy proposed by China takes economic construction as the explicit goal, but it also has a cultural perspective. The development of rural economy and culture cannot be satisfied by existing development forces. Therefore, investment in policies, financial resources, and human resources is required. After all, external investment is only a temporary solution. Rural revitalization should focus on long-term development. Such a development plan requires the village to have its endogenous motivation and a sound talent training mechanism. In turn, it can independently cultivate talents suitable for local development and gradually promote the development of the rural economy and the improvement of culture. This coincides with the idea that other countries in the world attach importance to rural education.

It is not rare to focus on rural development at the national level worldwide, such as Rural Renewal Planning in Germany. In some countries, development policies are directly linked to education and training. For example, Australia has implemented Vocational Education and Training to improve rural vocational skills.

Completing a comprehensive well-off society and poverty alleviation in 2020 marks a significant advancement in China's rural education. On May 14, 2021, the Ministry of Education and other four departments issued the Opinions on the Effective Linkage of the Consolidation and Expansion of Educational Poverty Alleviation and the Effective Connection of Rural Revitalization. As a result, the development goals at this stage have been clarified; that is, while consolidating the previous achievements in education poverty alleviation, it will further promote the faster development of rural education.

About the Author: Jie Wu, Education Bureau of Zhoucun District, Zibo City, Shandong, China. E-mail: jitj6413175@126.com

Correspondence to: Wei An, Education Bureau of Zhoucun District, Zibo City, Shandong, China. E-mail: zhcshyanw@163.com

Conflict of Interests: None. 
In this context, analyzing the defects of rural education at this stage, exploring the path of education to achieve revitalization, and timely retrospect the internal development of education under rural revival is the proper meaning of research education. In 2021, the "Opinions on the Implementation of the Rural Revitalization Strategy 20182022" issued by the Central and State Council is more than half of the process, and the historical task of poverty alleviation has just been completed. At such a critical time node, summarize the education field's thinking on rural revitalization and the measures that have been implemented since the policy was put forward in 2017, and make a timely grasp of the current research direction. It is conducive to a clearer understanding of the development route in the latter half of the "Guiding Opinions" construction plan. It can also make up for research shortcomings and improve the internal construction of education.

China divides the objectives of the rural revitalization strategy into three time periods, namely, "significant progress will be achieved in the rural revitalization strategy by 2020; decisive progress will be made by 2035, and rural revitalization throughout the year by 2050 ".

Based on the division of this period, it can be seen that the current stage is still in the early stage of the strategic layout of rural revitalization. During this period, education-related policies include Guiding Opinions on Comprehensively Strengthening the Construction of Rural Small-scale Schools and Rural Boarding Schools issued by the General Office of the State Council (hereinafter collectively referred to as Two Types of Schools). It pointed out that "the running of two types of schools is an important task for implementing the strategy of rejuvenating the country through science and education, accelerating the modernization of education, and a basic requirement for implementing the strategy of rural revitalization and promoting the equalization of basic public services in urban and rural areas." In addition, the Ministry of Education has also set up a major pedagogical bidding project, "Research on Rural Education Modernization in Rural Revitalization Strategies," in conjunction with the issue of educational modernization that has permanently been attached to it, intending to concentrate scientific research forces while promoting the parallel development of rural revitalization strategies and educational modernization.

Since the rural revitalization strategy was first proposed in 2017 , the research on the two-way relationship between policies and disciplines has become a research hotspot. There are various research positions and perspectives, but there is no macroscopic experience of this research yet. It summarizes the outlook of education for rural revitalization, the achievements made in 2018-2021, and the main problems faced at this stage. This research uses the relevant documents collected in China National Knowledge Infrastructure (CNKI). It uses the quantitative analysis method software Citespace to organize and analyze the research on "village revitalization" in the past 30 years. Then, based on the analysis results, the literature in the field of education under the background of rural revitalization is sorted out to clarify the features of the current research stage and provide references for subsequent teaching practice, theoretical analysis, and policy implementation. 


\section{Data Sources and Research Methods}

The research data in this article comes from CNKI. Set "rural revitalization" as a keyword in the literature search. The total number of journal articles published under this topic in the past 20 years was 27,300. Since the research object of this article is education research in the context of rural revitalization strategy, it is necessary to filter the preliminary inspection data further.

\section{Data Sources}

By searching CNKI's research that set the keyword as "rural revitalization," after placing the publication period from 2000 to 2021, more than 20,000 academic journal articles and 14 articles under the theme of "rural revitalization" can be retrieved as research results. The number of articles published in academic journals was small and stable from 2000 to 2016. However, it has gradually increased since 2017, reached its peak in 2019, and dropped slightly in 2020.

On this basis, the subject "Education" was superimposed to search, and the number of academic journal articles obtained was 2,702. The first article was published in 2012, and there has been a surge since 2018, and it will reach its peak in 2020.

However, it is worth noting that some of the keywords of rural education research carried out in the context of rural revitalization will appear in the form of "rural education." Still, the main text discusses the effect of "rural revitalization" on educational development. Therefore, if the theme is set as "rural education" and the full-text search of "rural revitalization" is superimposed, 1,606 journal studies can be obtained. Based on relevant data, we can get a trend chart of the research done in education in the past 20 years in the context of "rural revitalization".

The change in the number of publications of related articles is closely related to the trend of China's policy. In 2017, the "rural revitalization" strategy was first mentioned. In 2018, the Guiding Opinions were issued, and the preliminary plan for 20182022 was put forward. In 2019, the number of policy studies had increased sharply. In 2020, although it is still included in the development plan of the "rural revitalization" strategy, the overall focus is on poverty alleviation to achieve a comprehensive well-off society, and the research enthusiasm is slightly reduced. In 2021, the Central and State Council issued the Opinions on Comprehensively Promoting Rural Revitalization and Accelerating Rural Modernization, which made it clear that "rural revitalization" has become the focus of this year's policy. Combined with the National Strategic Plan for Rural Revitalization (2018-2022), research on the background of "rural revitalization" will be the focus and hot spot for a while.

\section{Analysis of the Proportion of Educational Research and Keyword Analysis}


In all the papers published in academic journals with the keyword "rural revitalization", classified by subject, the top 40 in the field of education are: "Higher Education" 565 (1.46\%), "Vocational Education" 441 (1.14\%), "Agricultural Basic Science" 423 (1.09\%), "Adult Education and Special Education" 366 (0.94\%), "Education Theory and Education Management" 262 (0.68\%). The above articles totaled 5.31\%. The results obtained can see the proportion of rural revitalization in the overall background.

Furthermore, the subject of "rural revitalization education" is used to search for specific research points in education.

The top 20 major categories are: agricultural economy, education theory, and education management, vocational education, adult education, and special education, political parties and mass organizations, higher education, culture, secondary education, computer software, and computer software applications, talent science and labor sciences, the party of China, elementary education, basic agricultural sciences, agricultural economics, ideological and political education, middle school politics and international politics, preschool education, library information and digital libraries, tourism, architectural science and engineering.

On this basis, further keyword searches are carried out to clarify the entry point of research. It is manifested in the overall subject background of pedagogy; the current Chinese scholars' research focus is on strengthening professional quality-related education, rural teachers-related issues, and the direction of rural cultural construction.

\section{Analysis of Research Authors and Source Journals}

\section{- Authors of Educational Research in the Context of Rural Revitalization Strategy}

By analyzing all the documents under the theme of "rural revitalization education" in the CNKI from 2000 to 2021 (January to June), the principal authors are Dequan Zhu of Southwest University, Wenwu Hao of Shaanxi Normal University, and Zhengde Xiao of Hangzhou Normal University. Among them, Dequan Zhu is devoted to the research of vocational education. He is involved in the relationship between vocational education and the rural revitalization strategy and the subject development of vocational education itself. Wenwu Hao is committed to researching the construction of village and township schools. He is bidding for the "Research on the Modernization of Rural Education in the Revitalization Strategy of Rural Areas”, a major project of China's National Social Science Foundation of Education. Zhengde Xiao's research center explores the role of teachers in the context of rural revitalization and expands the boundaries of the part of teachers.

\section{- The Source of Journals in the Context of Rural Revitaliza- tion Strategy}


The literature comes from core journals and the Chinese Social Science Citation Index (CSSCI). In addition, researchers choose to publish more articles: Education Research, Journal of Southwest University (Social Science Edition), Exploration and Contending, Modern Distance Education Research, and Guizhou Social Sciences.

Education Research is a social science journal dedicated to education theory and education management. The researcher's educational research under the background of rural revitalization published above mainly focuses on the theoretical construction of a macro perspective, such as the symbiotic relationship between urban and rural education. Southwest University is located in the southwest of China, and adjacent to Sichuan, Qinghai, Yunnan, and Guizhou, there are a large number of rural areas that need to be improved. Therefore, the educational research under the background of rural revitalization in this university is geographically reasonable.

Therefore, articles published in the Journal of Southwest University (Social Science Edition) are mainly based on the local conditions of rural areas to carry out a variety of research methods. Exploration and Contending is a comprehensive education journal. Most of its publications and research discuss the pattern of education construction under rural revitalization from the perspective of high-level education. The journal of Modern Distance Education focuses on adult education and special education, so the publication of articles is biased towards continuing education and the leading role of teachers. The journal focus of Guizhou Social Sciences is similar to that of the Journal of Southwest University (Social Science Edition), but it has specific concerns about ethnic minority regions.

\section{Research on the Research Perspectives and Results of Various Education Fields from the Perspective of Rural Revitalization}

\section{- Vocational Education Research under the Background of Rural Revitalization}

The achievements of rural vocational education are directly invested in rural construction and agricultural production and play the most direct role in the development of rural areas. Therefore, taking vocational and technical education and training as the core and forming a modern education system with rural characteristics ( $\mathrm{Du}, 2018)$ can become the backbone of the strategic layout of rural revitalization.

\section{- An Analysis of the Obstacles to the Development of Rural Vocational Education}

From the perspective of the development trend of China's vocational education research, since the Decision on Accelerating the Development of Modern Vocational Education and Modern Vocational Education System Construction Plan (2014-2020) were promulgated in 2014, the quality of rural vocational education research Gradually improve. 
Liu (2018) proposed that vocational education should promote its development while promoting the "hollow" governance process in rural areas and achieve mutual promotion and interaction. Based on the original research direction and research insufficiency of vocational education in China, combined with foreign research perspectives on the relationship between vocational education and rural development, it focuses on the relationship between vocational education and rural "hollowing" governance and expects to achieve both. Elements and structure are coupled to achieve coordinated development and benign interaction. In addition to proposing expectations, the author also predicts the resistance to achieving the target development pattern. In the current situation where rural vocational education lacks research and judgment on actual needs, it is difficult for vocational education to keep up with the requirements of industrial upgrading. The congenital defects of the teaching staff make it impossible to provide public services for rural needs effectively. Vocational education itself has a situation where cities are solid and rural areas are weak. The "short-board effect" restricts the rural areas from getting the education investment they deserve. Multi-party governance makes the subject unclear, and the policy cannot be effectively implemented.

\section{- Prospects for the Development Direction of Vocational Education un- der the Background of Rural Revitalization}

Rural vocational education is the fundamental driving force of rural revitalization and cultivates the talents needed to develop rural revival. It directly concerns all aspects of agricultural production and life. The value orientation of rural vocational education can firmly guide the construction of follow-up education. In the past, the value orientation of rural vocational education was relatively static and one-sided, unable to meet the requirements of the times. Some scholars pointed out that the value orientation of rural vocational education should be "livelihood, life and ecology" (Xie \& Yan (2019). While promoting the cultivation of rural technical talents, rural revitalization should be realized (Zhu \& Shi, 2021), to discover the dual-track parallel of educational development and rural revitalization.

Zhu \& Yan (2020) stipulated the logical path for the development of rural vocational education, that is, through the capacity building of the "self-system" of education, across other fields of "other-systems", and integrating the "super-system" of rural society. Furthermore, it demonstrates the publicity of rural vocational education and the continuous development of modernity in the form of results in multiple fields.

\section{- The Establishment of a New Training Model under the Background of Rural Revitalization}

The vast majority of the current agricultural labor force belongs to physical and traditional experience farmers. They lack professional self-confidence, lag behind in product awareness and personality concepts, and cannot realize the recognition and pursuit of "self-worth" in the process of rural revitalization and agricultural modernization. Ma \& Zhu $(2019,2020)$ put forward the concept of building a modern apprenticeship and the 
logic behind the construction of this talent training method through a series of articles. The modern apprenticeship system refers to the combination of work and studies teaching methods, with school-enterprise integration as the implementation path, allowing enterprises and workers to cultivate new-type professional farmers and construct a cross-border identity between quasi-professionals and students.

This training model advocates the establishment of production, education, and school-enterprise cooperation systems. Through apprenticeship contracts, schoolenterprise cooperation, and education system provision, they promote the cultivation of modern farmers who are "professional free," "professional self-confidence," and "modern self-consciousness." Constructing a modern apprenticeship to cultivate a new type of professional farmer analysis framework, allowing educated persons to receive training in the field of work-study alternation, enhance professional participation, and gradually develop farmers" "modern personality." We need to actively pursue the maximization of interests in modern agricultural industrialization and marketization and become the leading force in the modernization of agriculture and rural areas.

\section{- Research on Teacher Issues in the Context of Rural Revi- talization}

The research related to teachers in rural education is quite diverse and has become the intersection of multiple research fields.

\section{- The Plight of Teachers'Self-Development}

Among the measures to vigorously strengthen the development of rural compulsory education, the support for areas with weak rural education has a relatively prominent characteristic of focusing on "hardware" rather than "software". Pang et al. (2020) pointed out that this characteristic is most pronounced in rural elementary schools. In addition, the existing rural teachers have the problems of low professionalism and severe age structure imbalance. Therefore, to ensure the support of talents in rural education, it is necessary to provide teachers with solid salary, staffing, and title policies and specify reasonable training supplementary policies. The authors pointed out that it is not appropriate to one-sidedly emphasize academic qualifications in the teacher supplement policy but should consider the degree of subject adaptation to estimate the integration of new teachers.

One of the difficulties faced by teachers' personal development is the evaluation of professional titles. The number of senior professional titles of rural teachers is relatively low, and promotion is difficult. This restricts the professional development and remuneration of rural teachers. The predicament of the current rural teachers has restricted the professional attractiveness of rural teachers (Pang et al., 2019). Specifically for the preschool education teacher group, Hong et al. (2021) surveyed the number of rural preschool teachers, teacher faculty, salary, and professional development through designing questionnaires on the preschool teachers in the central region. They found that the number of preschool teachers in the central area is still unable to meet the Pre- 
school Faculty Staffing Standards (Interim) requirements. The proportion of teachers with relevant professional backgrounds and preschool teacher qualification certificates is relatively low, teachers' salaries are low, and there is insufficient development space. Under such a pattern, where the education undertakings in western China have received more guarantees, the data shows a "collapsed" appearance. Researchers define this phenomenon as "central collapse".

\section{- The Predicament of Teacher Responsibilities}

The researchers pointed out that the current rural education environment is not conducive to teachers' performance. Rural teachers have both the role of school education and influence on rural customs. However, it is difficult for rural teachers to play their professional role in the natural environment due to the obstacles of teachers' selfpreparation dilemma, the constructive dilemma of resources, and the adaptability dilemma of reforming ecology.

In addition to the reasons mentioned above that hinder teachers' responsibilities, Tang \& Wu (2019) focuses on parents' solidified thinking and expected effects on teachers' performance. The main impact of parents' solidified thinking is that rural parents have cognition that learning is useless, or have too practical expectations for the effectiveness of education, and lack an objective understanding of the long-term value of education, which hinders the effectiveness of teacher education. Furthermore, the expected effect on teachers' performance is that China has carried out basic education reforms in recent years, and not every reform has an apparent impact. Therefore, teachers will lose the motivation to accept the new overhaul, hindering teachers' development.

\section{- Promoting Rural Teachers to Play More Responsibilities in Rural Con- struction}

China released the Rural Teacher Support Plan (2015-2020) in 2015. By 2020, the Ministry of Education has issued the Notice on Further Implementing the Living Subsidy Policy for Rural Teachers; simultaneously, the Development and Reform Commission and other four departments jointly issued the Opinions on Strengthening the Construction of Rural Teachers in the New Era. This reflects the policy level's continuous attention to the development of rural teachers and the current shortcomings caused by teacher problems. Its focus can be roughly divided into two aspects: external stimulus and internal reinforcement. The measures to focus on external development include: guiding the flow of outstanding talents to the countryside, strengthening the training of rural teachers who meet the requirements of the new era, improving the social reputation of rural teachers, and improving the treatment of rural teachers and the humanistic environment of the living environment. The measures for construction from within the teacher group include: coordinating and increasing the living allowances for rural teachers, coordinating and optimizing the arrangement of rural teachers, and stimulating the endogenous motivation of teachers to contribute to rural education. 
Judging from the thinking of the existing research, most of them are consistent with the trend of the policy. Basically, it can be divided into the following directions:

First, Call for Policy Support and Make Specific Suggestions for Policy Construction.

The study by Tang et al. (2020) pointed out that among the favorable factors that affect the professional role of rural teachers, national policy support ranks first with a ratio of $85.8 \%$. Du (2018) pointed out that it is necessary to build education measures that focus on rural education and clarify policy directions. Finally, Pang et al. (2019) gave some detailed suggestions on the professional title system in terms of teacher treatment, including quota setting, job ratios, and policy preference for exceptional circumstances.

Zeng \& Gao's (2018) research was based on the implementation of the Rural Teacher Support Plan, and on the specific conditions of 12 counties in 6 provinces in the central and western regions, and explored the problems that still exist in the construction of the rural teacher team after strengthening policy support. It is deduced that the current policy has shortcomings on the structure of teachers and insufficient personalization of professional training content. These problems are more prominent in smaller schools. Based on this, they put forward the concept of empowering rural small-scale schools and teachers in small-scale rural schools. Provide personalized assistance to the teaching unit of "small-scale rural schools".

Second, Improve Professionalism and Cultivate Personal Beliefs.

Zeng \& Gao (2018) pointed out that after the state has made targeted support at the policy level, the personal literacy of teachers still has the problem of low information technology application ability. Meanwhile, the researcher also pointed out that the unreasonable structure of the teacher team is typical in rural schools. As a result, most teachers need part-time teaching, but their subject literacy is insufficient, and it isn't easy to meet the teaching standards. Accordingly, it is necessary to provide teachers with comprehensive training.

\section{- Exploration and Research of Educational Construction Path under the Background of Rural Revitalization}

Given the gap between the current education level and the goal of rural revitalization, scholars have proposed solutions to various problems in the overall vision of education.

\section{- The Practical Path for the Reform of Basic Education in Rural Areas}

First, the Layout of Rural Basic Education Schools

Jin et al. (2019) proposed that under the economic rational scale effect value orientation, some regions have implemented measures to withdraw sites and merge schools, the one-sided pursuit of resource concentration, and the lack of scientific demonstration of resource distribution planning has caused a deviation in the layout of educational resources. 
Under the background of differences in economic development, insufficient coordination of regional governments, and social transformation, it isn't easy to adjust educational resources objectively. These problems together led to the decline of rural schools and caused children in poverty-stricken areas to face issues such as longdistance and difficulty in going to school. The reduction in the number of students in school has, in turn, made the countryside lose its attractiveness to the workforce, resulting in rural revitalization with a hollow workforce. The authors propose corresponding rectification plans for resource allocation in this situation: (i) Take urban and rural areas as a whole for planning. (ii) Formulate scientific planning standards so that the layout of rural schools can be based on evidence. (iii) Use a variety of methods to promote the endogenous development of rural schools.

\section{Second, the Dual Barriers to Urban and Rural Education Caused by Resource Tilt}

Liu \& Feng (2019) conducted a particular study and pointed out that after the promulgation of Several Opinions on Promoting the Integrated Reform and Development of Urban-Rural Compulsory Education in Counties in 2016, some measures to simultaneously coordinate rural and urban educational resources have been launched. For example, the Rural Revitalization Strategic Opinions require the construction of a development system that integrates urban and rural areas and integrates regions. This kind of thinking can be used for reference in allocating educational resources and with the help of the policy background to obtain better implementation effectiveness.

\section{- The Conception of Targeted Training for Higher Education Boosting Rural Development}

Investing in rural construction by college students who have received higher education is an efficient way for rural areas to quickly obtain a large amount of high-quality human capital. Song (2019) analyzed the resistance of college students returning to their hometowns to start a business. He believes that the current design of the entrepreneurial policy for college students focuses more on "using entrepreneurship to drive employment" and aims to solve the employment problem. Still, the entrepreneurial risk is not fully controlled, resulting in a lack of motivation for college students to start a business. At the same time, there are still the problems of insufficient attractiveness of the rural environment, low enthusiasm, and inadequate experience of college students to return to their hometowns to start a business. Based on this, he put forward the idea of solving policy inclination, assistance in risk management, and flexible adjustment of policies to make this method obtain more excellent benefits.

The construction idea of higher education is to improve the training mechanism of agricultural talents and strengthen the construction of related disciplines. The "Midterm Plan for Rural Practical Talents and Agricultural Science and Technology Talents (2010-2020)" pointed out that the proportion of rural practical talents with specific knowledge and skills in the rural labor force is only $1.6 \%$. The main reasons for this situation are the current unreasonable educational background and employment struc- 
ture of agricultural-related talents. As a result, few agricultural-related talents enter the countryside, the difficulty in maintaining talents in the rural areas, the mismatch between the training talents and the required talents, etc. Liu \& Xue (2018) gradually cultivated high-quality talents for rural construction from the perspective of improving the government-led diversified talent training mechanism, building a highland of agriculture-related talents, strengthening school-enterprise cooperation, and establishing a talent database to enhance the connection between supply and demand.

Cheng \& Chen (2019) used a specific case from Huazhong Agricultural University to point out the implementation path of the rural revitalization strategy of the agricultural university to assist in implementing the rural revitalization strategy.

Ren \& Tang (2021) proposed a long-term idea of achieving coordinated development in teacher training and rural education. With rural education talents, educators who are suitable for the environment will be cultivated, and school-based textbooks ideal for rural areas will be developed simultaneously, integrating local concepts.

\section{Areas That Need to be Deepened in Educational Re- search under the Background of Rural Revitalization Strategy}

The research on rural revitalization strategy is currently in its infancy, and a timely grasp of the unreached areas of the study will help grasp the direction of the next stage of development.

\section{The Theoretical Research of Education Ontology in the Context of Rural Revitalization Has Limitations}

\section{- First, there was a Small Amount of Research in the Theo- retical Field of Teaching and Curriculum Design}

The part of the current research involving the teaching design of rural schools stays in the guidance of ideas and lacks a systematic and effective teaching plan. The study frequently mentions the concept of the urban-rural gap but remains at the material level and value level analysis. It did not point out the differences in knowledge system, cognitive style, and learning mode between urban and rural students. There was no prerequisite for studying suitable teaching programs for rural students.

\section{- Second, the Range of Research was Narrow}

The research on rural teaching in the United States, Australia, Canada, and other countries not only pays attention to the cultivation of human capital and the awareness of agricultural ecology but also involves the study of the system of special education. Although the previous data shows that "adult education and special education" has a con- 
siderable amount of publications, the specific research content is biased towards economic development through the training of adult production skills, and "special education" has become a gap. There is a particular academic journal of Rural Special Education Quarterly in foreign countries, which discusses related issues of the educated group with special needs, reflecting the comprehensive and balanced focus. Comparing China's current educational research in rural revitalization with the international research environment, there is a research blowout due to the proposal of policies. There are also many pieces of study focusing on the same issue where the line of sight is too narrow. On the contrary, the narrowing of the research field presents a simplification of the problem, which does not coincide with the complexity of the rural situation. Chinese scholars can adjust the research focus and pay as much attention as possible to all groups related to education to improve the "happiness" mentioned in rural revitalization in a balanced way.

\section{- Third, There was a Lack of Research on the Negative Ef- fects of Policies on Education}

The current research direction is mainly focused on the supporting role of education in reaching the goal of rural revitalization and how to maximize the professional part of teachers. However, as for the changes and innovations in the disciplines that support the revitalization policy in the education field, there is a lack of necessary attention. As a result, it has not risen to the level of theoretical research.

\section{- Lack of Dynamic Attention to Changes in Data}

Education serves as a driving factor for rural revitalization to provide talent support for the development of society and changes itself, and forms an innovation in the education system. This change has both distinctive characteristics of the times and the environment. The current research focuses mainly on promoting rural economic construction by educational practice and strengthening talent reserves. There is no research on the changes within education that education itself has produced in response to developmental changes. This is a worthy part of the subsequent research. Tracking a large number of curriculum practices and summarizing the course results may promote the deepening of pedagogy's research. This part of the research first appeared in the agricultural disciplines of higher education and belonged to the "most important" higher education reform research project. If it can be further expanded to basic and vocational education, it will complement the current lack of original teaching theory.

The researcher pointed out the problems in the number of rural teachers, the ratio of teachers to students, the age of teachers, and the number of staff. The scope of the discussion is basically placed on a national scale, and a few studies have selected specific cases in individual regions for analysis. However, reviewing the China Education Statistics Yearbook showed that since the "Rural Teacher Support Plan" was put forward in 2015, the data from 2016 to 2019 has changed significantly, including the number of preschools in the basic situation of preschool education. 83,884 in 2015 increased 
to 98,688 in 2019; border provinces such as Qinghai, Ningxia, Xinjiang, and Yunnan had the largest increase. Although the number of preschool teachers is not accurate to the province, it is also worth exploring the root causes behind the data changes from an overall perspective. The details of the significant pattern change still need to be studied by scholars. In addition to the longitudinal data analysis of chronological changes in a single region, the horizontal errors between provinces should also be considered compatible to explore the reasons for the dislocation of regional differences and various teaching elements. While tracing the data changes and the root causes behind them, it is worth noting whether the teaching results have made substantial progress. This part of the current research volume is relatively small, and it is worthwhile to focus more on it.

Another focus of the research on rural teachers is the internal construction of rural teachers. The internal construction situation most directly reflects the ratio of the number of teachers to the personnel composition of all types of teachers. According to the China Education Statistics Yearbook 2019, the total number of faculty and staff in rural elementary schools in 2019 was 1,795,347, of which 1,679,354 were full-time teachers, 63,394 were substitute teachers, and 14,761 were part-time teachers. Among them, the number of substitute teachers in Beijing and Zhejiang was zero, and the number of substitute teachers in Tianjin, Shanghai, Guizhou, and Yunnan was less than 100. Substitute and part-time teachers in rural elementary schools in Henan Province account for $5.3 \%$ of the total staff, and in middle schools was $1.46 \%$. Whether it was the latest 2019 data or 2016 data, Henan ranked first in the country. What kind of background allows Henan Province to have a large group of rural substitute teachers and part-time teachers? What are their treatment and teaching levels? These are all issues worthy of further investigation. However, the number and proportion of part-time teachers in Yunnan and Guizhou, a large rural population, were not high. What is the source of their formation? It can be compared horizontally with provinces with a large proportion of part-time and substitute teachers.

In the context of rural revitalization, the number of rural teachers, the improvement of the professional training of original teachers, and the specific implementation of similar policies in particular regions have not yet been sufficiently studied. Moreover, research comparing the situation before and after implementing rural revitalization-related policies is not very sufficient. Therefore, if the effectiveness of the policy is to be judged, it is imperative to follow up on the results of the policy promptly.

\section{- Unbalanced Efforts in Various Fields of Education}

The current research focus is mainly on vocational education, and the research in this field is also relatively comprehensive. In contrast, the research on preschool education and compulsory education appears to be out of balance. The current research in these fields is mainly on the distribution of teaching resources such as teachers, focusing on guiding policies to invest in this stage of education. However, the research on pedagogy and subject ontology is still in its infancy. The Humanities and Social Science Project of the Ministry of Education of China, Theoretical and Practical Exploration of Rural Education to Promote Rural Revitalization-Taking Zhejiang Anji as an Example is wor- 
thy of attention. At present, the research results on the teacher professional development model in the form of "the famous teacher studio" made by Tong et al. (2021) are rare cases derived from the specific practice and theoretical research.

In the follow-up research, we refer to the research paradigm of agriculturerelated disciplines in vocational and higher education. In basic education, the research point of view is placed on the construction of the subject itself, and basic education content and teaching methods suitable for rural areas have been explored.

\section{References}

Cheng, H., \& Chen, Y. (2019) Analysis of the Implementation Mode and Path of Agricultural University's Support for Rural Revitalization Strategy: Taking Huazhong Agricultural University as an example. Journal of Huazhong Agricultural University (Social Science Edition), 2019(4): 144-150+177. DOI:

https://doi.org/10.13300/j.cnki.hnwkxb.2019 .04 .016

China. (2018) "National Rural Revitalization Strategic Plan (2018 2022)" http://www.gov.cn/zhengce/201809/26/content 5325534.htm

Chinese Central and State Council. (2018) "Opinions on the Implementation of the Rural Revitalization Strategy"

http://www.gov.cn/gongbao/content/2018/co ntent_5266232.htm

Chinese Central and State Council. (2018) "Several Opinions on Deepening Reform and Standardization of Preschool Education" http://www.gov.cn/zhengce/201811/15/content 5340776.htm

Chinese Central and State Council. (2021) "Opinions on Comprehensively Promoting Rural Revitalization and Accelerating Rural Modernization" http://www.gov.cn/zhengce/202102/21/content 5588098.htm

Chinese Central and State Council. "China Education Modernization 2035" http://www.gov.cn/xinwen/201902/23/content 5367987.htm

Department of Development Planning, Ministry of Education of China. (2017) "China Education Statistics Yearbook 2016", Beijing: People's Education Press. ISBN: 9787503781872

Department of Development Planning, Ministry of Education of China. (2020) "China Education Statistics Yearbook 2019”, Beijing: People's Education Press. ISBN: 9787503793936

Du, Y., \& Yang, X. (2018) Rural Revitalization: Rural Education as a Strategic Support and Its Development Path. Journal of South China Normal University (Social Science Edition), 2018(2): 76-81+192.

Hong, X., Du, H., \& Zhang, M. (2021) Thinking and Governance of "Central Collapse" in the construction of kindergarten teachers in the context of rural revitalization strategy. Journal of Central China Normal University (Humanities and Social Sciences Edition), 60(2):170-178.

General Office of the State Council of China. (2015) Rural Teacher Support Plan (20152020) (Guobanfa [2015] No. 43), 09-08

Jin, Z., Pang, L., \& Yang, X. (2019) The layout of urban and rural compulsory education schools under the background of rural revitalization strategy: realistic problems and path thinking. Journal of Beijing Normal 
University (Social Science Edition), 2019(5): $5-12$.

Liu, A., \& Xue, E. (2018) Analysis of the agricultural talent training system and mechanism involved in the perspective of rural revitalization. Educational Theory and Practice, 38(33): 3-5.

Liu, F. (2018) The coupling of vocational education and rural "hollow" governance under rural revitalization. Journal of National Academy of Educational Administration, 2018(7): 40-46.

Liu, L., \& Feng, L. (2019) Analysis of promoting the integrated development of urban and rural compulsory education. Journal of Hebei Normal University (Educational Science Edition), 21(3):5-8. DOI:

https://doi.org/10.13763/i.cnki.jhebnu.ese.20 $\underline{19.03 .001}$

Ma, X., \& Zhu, D. (2019) The logical framework for the modern apprenticeship mechanism to cultivate new professional farmers. Journal of the National Academy of Educational Administration, 2019(9): 87-95.

Ma, X., \& Zhu, D. (2020) Exploring the Path to Develop Modern Apprenticeship and Cultivate New Type of Professional Farmers. Educational Development Research, 40(21):7176. DOI:

https://doi.org/10.14121/j.cnki.1008$\underline{3855.2020 .21 .011}$

Ministry of Education of China, National Development and Reform Commission, Ministry of Finance, National Bureau of Rural Revitalization. (2021) "Opinions on Consolidating and Expanding Educational Poverty Alleviation and Effective Linkage of Rural Revitalization" (Jiaofa [2021] No. 4), 05-07

Pang, L., Jin Z., Yang X., Wang H. (2020) Improving the construction of the teaching staff to help rural revitalization strategiesinstitutional thinking and policy recommendations. Journal of Beijing Normal University (Social Science Edition), 2020(6): 5-14.

Pang, L., Yang, X., \& Jin, Z. (2019) Difficulties, influences and policy responses of rural teachers' professional title evaluation. Teacher Education Research, 31(1):31-36. DOI: https://doi.org/10.13445/j.cnki.t.e.r.2019.01. $\underline{006}$

Ren, Y., \& Tang, S. Analysis on the Path of Coordinated Development of Rural Education and Local Normal Colleges. China University Humanities and Social Sciences Information. Network.

https://www.sinoss.net/show.php?contentid= 101496

Song, H. Research on college students returning to their hometowns to start a business under the background of the rural revitalization strategy in 2019. Education and Career, (22): 58-61. DOI:

\section{https://doi.org/10.13615/i.cnki.1004-} 3985.2019.22.011

Tang, Y., \& Wu, Z. (2019) The Dilemma and Path of Rural Basic Education Reform in the New Era. Contemporary Education and Culture, 11(3):58-63. DOI: https://doi.org/10.13749/j.cnki.cn62$\underline{1202 / g 4.2019 .03 .010}$

Tong, F., Li, D., \& Du, Y. (2021) An Empirical Study of Famous Teacher Studios and Teacher Professional Growth-Based on Surveys and Interviews of 225 Famous Teacher Studios. Journal of Ningbo University (Educational Science Edition), 43(3):6673.

Wu, C. (2018) Foreign Rural Education Research: Current Status, Hot Spots and Enlightenment-Taking 2014-2018 ERIC Database Papers as an Example. Foreign Elementary and Secondary Education, 2018(12):3849.

Xi, J. (2017) Decisive victory for building a moderately prosperous society in an allround way and winning the great victory of socialism with Chinese characteristics in the new era. People's Daily, 10-28 (001).

Xie, Y., \& Yan G. (2019) The expected value orientation of rural vocational education: livelihood, life and ecology-from the perspective of rural revitalization strategy. Educational Development Research, 39(1):10$16+39$. DOI: https://doi.org/10.14121/j.cnki.1008$\underline{3855.2019 .01 .004}$ 
Ye, X. (2018) Outline of China's Rural Revitalization Strategy in the New Era. Reform, 2018(1): 65-73.

Zeng, X., \& Gao, Z. (2018) Empowerment and Empowerment: The Road to Building a Contingent of Teachers in Rural Small-scale Schools in the Context of Rural Revitalization-Based on a survey of the implementation of the Rural Teacher Support Plan in 12 counties in 6 provinces in central and western China. Central China Normal University Journal (Humanities and Social Sciences Edition), 57(1): 174-187.

Zhang, G. (2018) Rural education is education "in the countryside". Basic Education, 15(3):1.

Zhu, C., Yan, G., \& Zhu, D. (2019) Rural construction and rural education: vocational education targeted poverty alleviation integration model and rural revitalization strategy.
Journal of East China Normal University (Education Science Edition), 37(2): 127-135. DOI: https://doi.org/10.16382/j.cnki.10005560.2019.02.014

Zhu, C., \& Yan, G. (2020) Crossover and Symbiosis: An Analytical Framework for the Integration and Governance of Rural Vocational Education. Educational Research and Experiment, 2020(1): 20-28.

Zhu, D., \& Li, X. (2019) 70 Years of Research on Rural Vocational Education in China: Research Evolution and Paradigm Reflection. Journal of Southwest University (Social Science Edition), 45(6): 5-19+201. DOI: https://doi.org/10.13718/j.cnki.xdsk.2019.06. 001

Zhu, D., \& Shi, X. (2021) Technical logic and value purpose of vocational education serving rural revitalization. China Audio-visual Education, 2021(1): 41-49. 